\title{
Parasitos de Balistes vetula (L.) e sua importância na inspeção do pescado
}

\section{Parasites of Balistes vetula (L.) and their importance in fish inspection}

\author{
Sérgio Carmona de São Clemente ${ }^{1}$, Francisco Carlos de Lima $^{2}$ e Claudia Maria Antunes Uchoa ${ }^{3}$
}

\begin{abstract}
Resumo
Foram examinados 50 peixes da espécie Balistes vetula $L$., pescados no litoral do Estado do Rio de janeiro, com o objetivo de se detectar larvas de cestóides da ordem Trypanorhyncha e larvas de nematóides anisakídeos. Os peixes apresentavam comprimentos entre 17 e $28 \mathrm{~cm}$, sendo que aqueles com médias compreendidas entre 24 e $28 \mathrm{~cm}$ achavam-se mais infectados. Do total de espécimens necropsiados, $88 \%$ achavam-se parasitados. por cestóides Trypanorhyncha das espécies Callitetrarhynchus gracilis, Callitetrarhynchus speciosus e pelo gênero Otobothrium e 56\% achavam-se parasitados por larvas de anisakideos do gênero Contracaecum.
\end{abstract}

Palavras-chave: parasitos, Balistes vetula, Inspeção

\section{Introdução}

Na inspeção do pescado, a presença de larvas de cestóides da ordem Trypanorhyncha e nematóides da família Anisakidae, podem fazer com que o consumidor o descarte, pelo aspecto repugnante que estes parasitos conferem ao peixe. No Brasil, Faria \& Silva (1934) citaram a ocorrência de larvas de Trypanorhyncha em 21 espécies de peixes desembarcadas no entreposto de pesca da Cidade de Rio de Janeiro. Santos \& Zogbi (1971) assinalaram que $15 \%$ de 23.415 filés de seis espécies de peixes teleósteos pesquisados na Cidade do Rio Grande-RS, estavam parasitados com larvas de Trypanorhyncha. São Clemente (1987), no Rio de Janeiro, chamou a atenção sobre a presença de lavas de cestóides em corvinas (Micropogonias furnieri) e sua importância na inspeção do pescado. Com o intuito de atender a reclamações de importadores europeus de bonito (Katsuwonus pelamis), feitas às autoridades brasileiras, de que os peixes "continham vermes", Amato et al. (1990) realizaram pesquisas sobre a presença de
Tentacularia coriphaenae na musculatura de K. pelamis. São Clemente et al. (1993) assinalaram a presença de Dasirhynchus giganteus localizada na musculatura da cabeça de xaréu (Caranx hippos), pescados no litoral do Pará. Nos Estados Unidos, Overstreet (1977) e Deardorff et al. (1984) chamaram a atenção sobre a presença de plerocercos da ordem Trypanorhyncha, em peixes de interesse comercial. Kikuchi et al. (1981) descreveram um caso de parasitismo humano por larva de Trypanorhyncha, ocorrido no Japão.

Os estudos sobre a importância dos parasitos de peixes de interesse comercial no Brasil, visando a Inspeção Sanitária do Pescado, ainda são bastante reduzidos. Por isso, o presente trabalho tem como finalidade fornecer subsídios aos Serviços de Inspeções Federal, Estadual e Municipal.

\section{Material e Métodos}

Foram examinados 50 espécimes de Balistes vetula pescados no litoral do Estado do Rio de Janeiro, por pescadores profissionais. Os peixes foram medidos e eviscerados. Com a cavidade aberta fez-se os exames e coleta das larvas que encontravam-se nas serosas das vísceras e paredes da cavidade geral. Em seguida, foram retirados os filés, para verificar a existência ou não de parasitos na musculatura. Os cestóides coletados foram liberados dos blastócistos e colocados em placa de petri contendo água destilada e mantidos no refrigerador por 24 horas, para que morressem com os tentáculos distendidos. Em seguida; foram fixados em AFA (álcool 70\% - formalina - ácido acético) frio, corados pelo carmin de langeron, diferenciados em álcool clorídrico a 0,5\%, desidratados pela série alcoólica crescente, clarificados pelo creosoto de Faia e montados em bálsamo do Canadá para posterio identificação. Os nematóides foram fixados em AFA quente, mantidos em álcool

\footnotetext{
1 Professor Titular, Faculdade de Veterinária-UFF, Bolsista CNPq, C.P. 100.086 - CEP.: 24230.340 - Niterói - RJ - Brasil

2 Professor Adjunto, Faculdade de Veterinária-UFF, C.P. 100.086 - CEP.: 24230-340 - Niterói - RJ - Brasil

${ }^{3}$ Bolsista Iniciação Científica
} 
glicerinado a 5\%, clarificados pelo lactofenol de Aman e. quando necessário, montados em bálsamo do Canadá e identificados.

\section{Resultados}

Das 50 necrópsias realizadas de B. vetula, 88\% achavam-se parasitados por cestóides da ordem Trypanorhyncha (Figs. 1a e 1b) e 56\%, por nematóides da família Anisakidae. Dos peixes parasitados por larvas de cestóides, $10 \%$ apresentavam parasitos na massa muscular A localização das larvas de anisakídeos estava restrita às serosas das vísceras e da cavidade geral. Os plerocercos de cestóides coletados, pertenciam às espécies
Callitetrarhynchus gracilis, C. speciosus e ao gênero Otobothrium. As larvas de anisakídeos encontradas, pertenciam ao gênero Contracaecum. Os peixes pesquisados variavam de 17 a $28 \mathrm{~cm}$ de comprimento. Aqueles na faixa de 24 a $28 \mathrm{~cm}$, encontravam-se mais parasitados, sendo 97 o número máximo de larvas de Trypanorhyncha encontrados em um só peixe, e de 33, o máximo de larvas de anisakídeos. Apesar das espécies de cestóides encontradas não possuírem potencial zoonótico, suas presenças, principalmente quando localizados na musculatura, transferem ao peixe um aspecto repugnante, fazendo com que este seja descartado pelo consumidor ou condenado pelos Serviços de Inspeção.
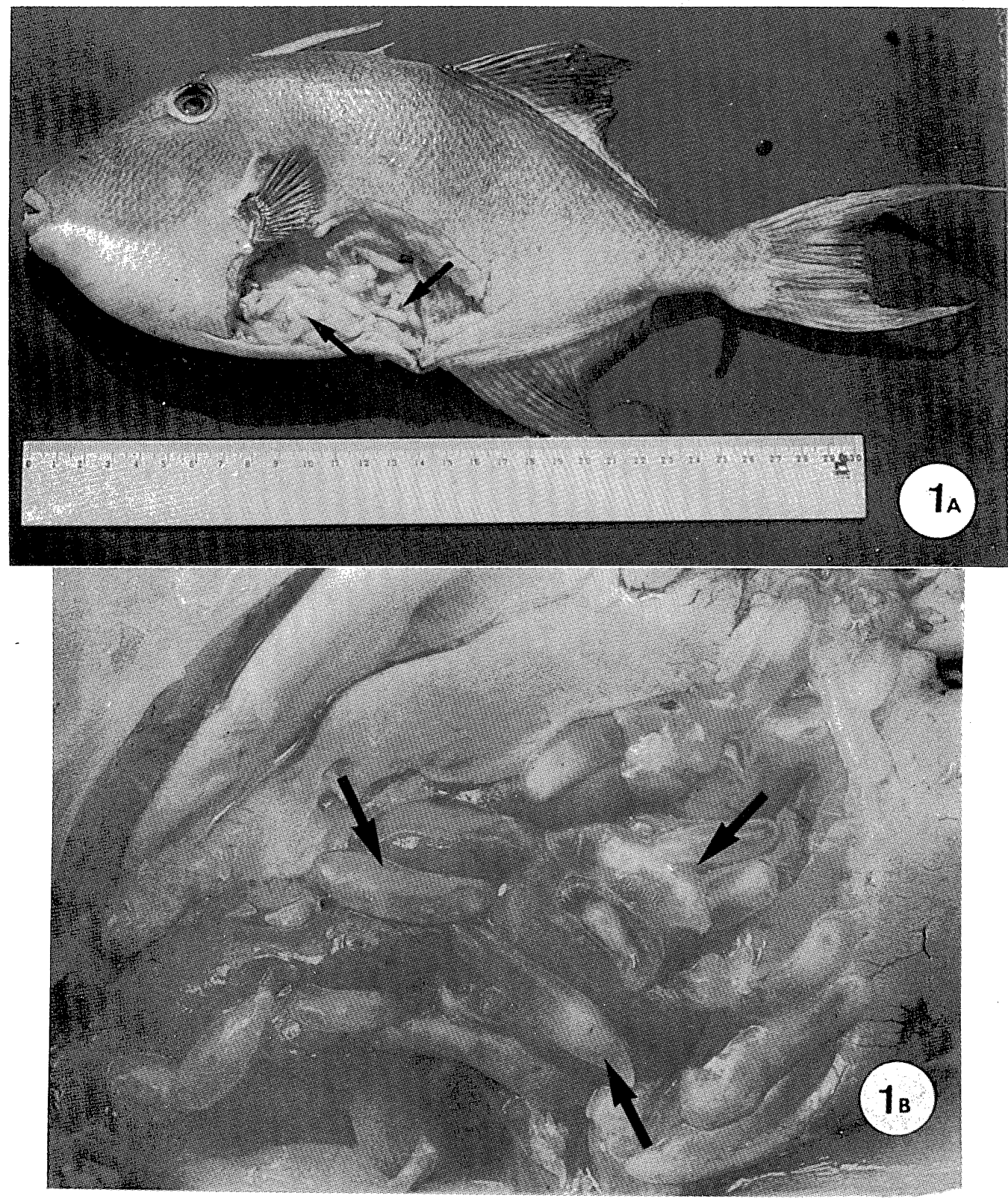

Figs. (1a e 1b): Blastocistos de Trypanorhyncha nas serosas das vísceras de Balistes vetula. 


\section{Discussão}

Segundo Deardorff et al. (1984) a localização de larvas de Trypanorhyncha na musculatura dos peixes, pode produzir toxinas e consequentemente afetar o consumidor, além do aspecto repugnante que estes parasitos conferem ao peixe. $O$ encontro de apenas $10 \%$ de $B$. vetula positivo para cestóides Trypanorhyncha localizados na massa muscular, é, portanto, um dado importante- No Japão, Kikuchi et al. (1981) descreveram o encontro de uma larva de Trypanorhyncha da espécie Nybelinia surmenicola, fixada no palato mole de um consumidor que havia ingerido alimento elaborado com pescado crú. A ocorrência no entando, foi considerada como uma infecção acidental.

O paràsitismo por este grupo de cestóides, em peixes, acredita-se ser acumulativa. Os peixes maiores do presente trabalho, encontravam-se mais parasitados; dados estes também registrados por Lester et al. (1985), Amato et al. (1990) que pesquisaram cestóides da ordem Trypanorhyncha em K. pelamys. Este fato foi também assinalado por São Clemente (1987) e São Clemente et al. (1993) em corvinas (Micropogonias furnieri) e xaréu (Caranx hippos), respectivamente. A ocorrência de cestóides Trypanorhyncha em espécie de peixes utilizadas para consumo humano e sua importância na inspeção de pescado, foram também enfocadas por Santos \& Zogbi (1971), São Clemente (1987), São Clemente et al. (1991 e 1993) e Amato et al. (1990) no Brasil, e, por Overstreet (1977) e Deardorff et al. (1984), nos Estados Unidos. O encontro de nematóides da família Anisakidae em B. vetula, mesmo não estando localizados na musculatura, é preocupante pelo possível potencial zoonótico destes helmintos.

\section{Abstract \\ Parasites of Balistes vetula (L.) and their importance in fish inspection}

Fifty specimens of the species Balistes vetula (L.) captured along the coast of Rio de Janeiro State were examined to detect cestode larvae belonging to the order Trypanorhyncha and nematodes anisakids larvae. The fishes measured from
17 to $28 \mathrm{~cm}$. $88 \%$ of them were parasited by Trypanorhyncha cestode of the species Callitetrarhynchus gracilis, Callitetrarhynchus speciosus and by the genus Otobothrium. 56\% were parasited by anisakids larvae of the genus Contracaecum. Specimens between 24 and $28 \mathrm{~cm}$ were found more parasited.

Key words: Parasites, Balistes vetula, Inspection

\section{Referências Bibliográficas}

AMATO, J. F. R., SÃO CLEMENTE, S. C. DE, OLIVEIRA, G. A. Tentacularia coryphaenae Bosc, 1801 (Eucestoda: Trypanorhyncha) in the Inspection and Technology of the Skipjack Tuna, Katsuwomus pelamis (I.) (Pisces: Scombridae). Atlantica v. 12, n. 1. p. $73-77,1990$

DEARDORFF, T. L., RAYBOURNE, R. B., MATTIS, T. E. Infections With Trypanorhyncha Plerocerci (Cestoda) in Hawaiian Fishes of Commercial Importance. Sea Grant Quartely. v. 6, n. 3, p. 1-6, 1984.

FARIA, A., SILVA, R. D. Garoupa Vermelha de Abrolhos e São Tomé "Garoupa Bichada" Tetrarhynchus (Primeira Nota). $1^{\circ}$ Congresso Nacional de Pesca, Rio de Janeiro. Anais, v. 1, p. 237-250, 1934.

KIKUCHI, Y., TAKENOUCHI, K. M. T., DZANI, O. Trypanorhyncha Cestode Larva Found on the Palatine Tonsil. Jap. J. Parasitol. v. 30, p. 497-499., 1981

LESTER, R. J. G., BARNES, A., HABIS, G. Parasites of Skipjack Tuna Katsuwomus pelamis. Fishery Implications. Fish. Bull., v. 83, p. 343356, 1985

OVERSTREET, R.M., Poecilancistrium caryophyllum and Other Trypanorhyncha Cestode Plerocercoid from Musculature of Cynoscion nebulosus and Other Sciaenid Fishes in the Gulf of Mexico. J. Parasitol, 63 (5): 780-789, 1977.

SANTOS, C. A. M. L., ZOGBI, P. V. La infestacion de Peces em Brasi com Larvas de Tetrarhynchus fragilis. In: FAO. Fish Inspection and Quality Control. Roma: 1971. p. 262-264.

SÃO CLEMENTE, S. C. de. Plerocercos de Cestóides da Ordem Trypanorhyncha em Corvina Micropogonias furnieri (Desmarest) e sua Importância na Inspeção Sanitária do Pescado. Arq. Flum. Med. Vet. v. 2, n. 3, p. 82-83, 1987

SÃO CLEMENTE, S. C. de, COELHO, M. R. T., SERRA FREIRE, N. M. Cestóides Parasitos de Bagre Netuma barba (Lacepede, 1803) Pescados no Litoral do Rio de Janeiro e Comercializados para Consumo Humano. Arq. Flum. Med. Vet. v. 14, n. 1, p. 27-34, 1991.

SĀO CLEMENTE, S. C. de, MATOS, E, UCHOA, C. M. A., MATOS, P. Trypanorhyncha Plerocerci in Fish of Commercial Importance in Brazil. Parasitol. al Dia. v. 17, p. 51-53, 1993 